\title{
Case Study of Teaching Meta Communicative Competence Issues in Learners with ID
}

\author{
Saimkulova Sholpan ${ }^{1}$, Chaklikova Assel ${ }^{1}$, S.A. Odanova ${ }^{2}$, R. Rakhmatova ${ }^{2}$ and \\ Kapessova Taniya ${ }^{3}$
}

${ }^{1}$ Abali khan KUIRWL, Almaty, Kazakhstan

${ }^{2}$ KazSWPU, Almaty, Kazakhstan

${ }^{3}$ Almaty, Kazakhstan

\begin{abstract}
Nowadays, the fact of lack of knowledge of bilingualism due to the changed volume ratio in the teaching of writing is becoming more and more apparent, especially to learners with intellectual disabilities. The emergence of complex processes marks this fact is interference and convergence of speech, which are sources of better speaking and writing in bilingualism.

The purpose of the study is to identify the specific difficulties of teaching writing to younger bilingual schoolchildren with ID and to develop a productive speech therapy system for the prevention and correction of violations of higher mental functions that they have.

The object of research is the features of teaching children with speech deficiency and with ID to writing in bilingual conditions.

The subject of the research is the process of preventing and overcoming problems in the bilingual conditions of teaching children with speech and ID functions deficiency.
\end{abstract}

Keywords: Case study, bilinguals, aspects, learners, special needs, ID.

\section{INTRODUCTION}

It has been said many times in many ways that communication is the essence of life. One can see it when individual glances or gestures to share feelings with a family member or uses a microphone to lecture audience. These two essential purposes of communication - Socialization and information transfer - can be accompanied by individuals with a wide range of abilities and disabilities not only through natural speech and writing but also through Augmentative and Alternative Communication (AAC), especially in case of autism. In recent years AAC, which is the supplement or replacement of spontaneous speech and /or writing, has allowed many individuals with disabilities to more fully realize their potentials and enjoy the essence of life. It is important to note that there is not just one type of AAC. Rather, AAC encompasses a whole range of different activities which includes facial expression, eye pointing, gesture, signing symbols, spelling out a message on a letter board or computer, electronic speech output aids etc. Augmentative communication is an alternative way to help students and adults with language disorders use expressive language or receptive language [1]. Augmentative communication can be accomplished through assistive technology

*Address correspondence to this author at the Kazakh State National University of Al-Farabi, Almaty, Kazakhstan; Tel: +77073851878 ;

E-mail: zhanat_2006@mail.ru devices such as computers or handheld devices. Low technology, such as picture communication systems can also be used as Augmentative Communication. We communicate to satisfy our needs, which keep on changing from time to time. We need to meet our needs, get information, and interact with people and so on. This exchange of information is not possible without a tool which should be familiar to both speaker and listener [2]. Man invented a language for this purpose, makes communication easier. There is a dynamic relationship between children's language and their needs, regulate their own and other people's behaviour. Children with developmental language or speech disorders frequently benefit from augmentative and alternative communication (AAC) strategies [1]. These children have severe expressive or receptive communication disorders or both which sometimes occur in isolation, or as part of a global developmental disorder, developmental apraxia of speech, autism, Down syndrome, or other types of developmental disabilities may need to use AAC strategies to supplement or enhance their language development [3]. Today, professionals realize that AAC strategies can provide children who have developmental delays with an immediate means of communication; can facilitate expressive and receptive language development until other communication modalities improve (i.e. speech), and can serve as a bridge to future spoke language development [1]. 
For individuals with Intellectual Disabilities, chronological age is often linked to language development level, and together, these two factors may influence the outcomes of AAC interventions in complex ways. The majority of research about individuals with Intellectual Disabilities who employ $A A C$ are at least school aged. There has been a little empirical investigation about the use of AAC intervention at a very young age. The more significant the developmental delay, the more important it may be to initiate response early in childhood to ensure steady developmental progress [4].

For children, education must foster the acquisition of not only academic skills but also language and communication, socialization and adaptive behaviour. Practices in the education of children with Intellectual Disabilities emphasize need-based use of AAC strategies to facilitate communication and social participation. The result of the study conforms to the above findings. AAC training and usage were effective in enhancing language and communication and also the social behaviour of children with Intellectual disabilities [1].

\section{METHODS}

\section{Participants}

The study was done on a group of a hundred Kazakh undergraduate learners in two schools in Almaty city.

Most of the learners were juniors (66\%), while $34 \%$ were seniors. In terms of gender, the learners did not balance with 87 Females (87\%), 13 males (13\%) and their age ranged from 16 to 20 .

Following the designated purpose and tasks, the following research methods were used in work:

Table 1: A Self-Assessment Tool of Writing Skills (Questionnaire)

\begin{tabular}{|l|}
\hline Date \\
\hline Name \\
\hline Topic of writing \\
\hline $\begin{array}{l}\text { I used a repertoire of strategies to write with other members in my } \\
\text { group. }\end{array}$ \\
\hline $\begin{array}{l}\text { The strategies I used helped me write with other members in my } \\
\text { group more efficiently and thoughtfully }\end{array}$ \\
\hline The writing strategies I found most useful were \\
\hline The writing strategies I found difficult to use were \\
\hline
\end{tabular}

Organizational (comparative, complex); empirical (observation, test tasks, teaching and control experiments);

Statistical (quantitative and qualitative analysis, synthesis of research results).

\section{RESULTS}

The contingent of children studied was made up of secondary school learners from families where the native language is different. The study was conducted because of secondary school number 1 of $K Z$, enrolled in the program of education of national minorities.

Training takes place mainly in two languages, that is, in mastering the educational material, the native and foreign languages are equally used. Native language and 3-4 academic subjects are taught in the native language.

The experimental study covered: 100 children of the second and third grades, among which, based on the analysis of the letter

The theoretical significance of the study is determined by the following:

- $\quad$ The existing theoretical ideas about the brain mechanisms of mastering the letter in terms of bilingualism were expanded;

- the principles, directions, methods and conditions of the speech therapy work to overcome the disgraphics with children in the context of bilingualism are scientifically substantiated and defined.

The practical significance of the study is that the data obtained in the survey expand and clarify the ideas of efficient specialists (speech therapists, teachers) about the nature of the difficulties children experience in learning to write and ways to overcome them (in addition to those contained in the available literature).

It is also essential that thanks to the research, it became possible to develop guidelines for preventing and overcoming $\mathrm{h}$ dysgraphia in bilingual children, which contains:

A system of corrective exercises to improve the essential writing functions that determine the degree of readiness of children to learn writing; 
Methods of developing the necessary acoustic, phonetic is phonemic, phonemic is graphic, and other internalizes differentiations; ways to reduce the level of language interference (letter mixing, highlighting the differential features of sound is letter associations characteristic of both languages);

The rationale for the use of critical thinking methods in the lessons of the native language (innovative corrective is a pedagogical approach) [5].

The completed study has confirmed the existing ideas about dysgraphia and dyslexia and allowed them to reveal their specific features in bilingualism. Besides, it showed the importance of preventing speech development disorders. It is that necessary:

Timely identification of risk groups, which include children:

- With several perils is and postnatal effects;

- With late and abnormal development of oral speech;

- With mental retardation;

- With pronounced immaturity of visual abilities;
- Unavailability of bilingualism.

With these children, it is necessary to carry out correctional and preventive work in the following areas:

- $\quad$ Correction of phonetic and phonemic disorders;

- $\quad$ The formation of a functional basis of writing;

- Individualization of the pace and methods of teaching writing.

Besides, prevention is that in the selection of teaching methods, the profile of hemispheric asymmetry taken into account (relatively speaking, the severity of left is handedness or ambistria) [6].

Items 1, 11, 16, 19, 22, 23, 29 and 31 cover about foreign language aptitude. Item 16, 19, 22 and 31 address the concept of special abilities for language learning. Items 1, 23 and 11 address the characteristics of potentially successful language learners. Table 2 shows the participants' responses to the items in this category. Both GROUP 1 and GROUP 2 students reported somewhat similar opinions. For instance, 92 per cent of the students from GROUP 1 and 96 per cent of the GROUP 2 students felt that it is easier for children than adults to learn a foreign language.

Table 2: Survey Results: Foreign Language Aptitude

\begin{tabular}{|c|c|c|c|c|c|}
\hline Item & Source & AG & DA & M & SD \\
\hline \multirow{2}{*}{$\begin{array}{l}\text { 1. It is easier for children than adults to } \\
\text { learn a foreign language. }\end{array}$} & *GROUP 1 & $92 \%$ & $4 \%$ & 1.76 & 0.70 \\
\hline & \#GROUP 2 & $96 \%$ & $4 \%$ & 1.61 & 0.70 \\
\hline \multirow{2}{*}{$\begin{array}{l}\text { 11. Women are better than men at learning } \\
\text { foreign languages. }\end{array}$} & *GROUP 1 & $15 \%$ & $50 \%$ & 3.5 & 0.97 \\
\hline & \# GROUP 2 & $25 \%$ & $39 \%$ & 3.22 & 1.23 \\
\hline \multirow{2}{*}{$\begin{array}{c}\text { 16. Some people are bored with unique } \\
\text { ability which helps them learn a foreign } \\
\text { language. }\end{array}$} & *GROUP 1 & $58 \%$ & $24 \%$ & 2.56 & 1.09 \\
\hline & \#GROUP 2 & $59 \%$ & $14 \%$ & 2.44 & 1.05 \\
\hline \multirow{2}{*}{$\begin{array}{l}\text { 19. It is easier for someone who already } \\
\text { speaks a foreign language to learn another } \\
\text { one. }\end{array}$} & *GROUP 1 & $76 \%$ & $6 \%$ & 2.13 & 0.75 \\
\hline & \#GROUP 2 & $74 \%$ & $11 \%$ & 2.15 & 0.94 \\
\hline \multirow[t]{2}{*}{ 22. I have a foreign language aptitude. } & *GROUP 1 & $78 \%$ & $4 \%$ & 2.2 & 0.66 \\
\hline & \#GROUP 2 & $68 \%$ & $5 \%$ & 2.2 & 0.78 \\
\hline \multirow{2}{*}{$\begin{array}{l}\text { 23. People who are good at math and } \\
\text { science are not suitable for learning a } \\
\text { foreign language. }\end{array}$} & ${ }^{*}$ GROUP 1 & $15 \%$ & $73 \%$ & 3.69 & 1.15 \\
\hline & \#GROUP 2 & $29 \%$ & $52 \%$ & 3.34 & 1.3 \\
\hline \multirow{2}{*}{$\begin{array}{l}\text { 29. People who speak more than one } \\
\text { language well are brilliant. }\end{array}$} & ${ }^{*}$ GROUP 1 & $78 \%$ & $7 \%$ & 2.00 & 0.87 \\
\hline & \#GROUP 2 & $74 \%$ & $11 \%$ & 2.19 & 0.94 \\
\hline \multirow{2}{*}{$\begin{array}{l}\text { 31. Everyone can learn to speak a foreign } \\
\text { language. }\end{array}$} & *GROUP 1 & $90 \%$ & $2 \%$ & 1.54 & 0.79 \\
\hline & \#GROUP 2 & $92 \%$ & $3 \%$ & 1.64 & 0.77 \\
\hline
\end{tabular}

Note: $\mathrm{AG}=$ agree, $\mathrm{DA}=$ disagree, $\mathrm{M}=$ mean, $\mathrm{SD}=$ Standard deviation. The percentages (\%) have been rounded to the nearest tenth. 
Almost a quarter of both groups believed that women are better than men at learning foreign languages. However, nearly the same per cent $(58 \%$, $59 \%)$ students agree that some people are bored with a unique ability which helps them learn a foreign language. Also, $76 \%$ of students from GROUP 1 and $74 \%$ of students from GROUP 2 agree that it is easier for someone who already speaks a foreign language to learn another one. Almost three-quarters of students from both schools believe that they have foreign language aptitude. Interestingly, very a smaller number of students likes $15 \%$ and $29 \%$ from both schools agree the idea of people who are good at math and science are not good learners of foreign language, 78 per cent from GROUP 1 and 74 per cent from GROUP 2 agree with the beliefs about people who speak more than one language well are very intelligent. Nearly all students from both universities $(90 \%, 92 \%)$ believe that everyone can learn to speak a foreign language.

\section{DISCUSSION}

The study, including the recital and the forming experiments, gives grounds for conclusions:

1. Analysis of scientific literature in the field of logo neuropsychology allowed us to identify critical approaches to the study: pedagogical (speech therapy), linguistic, neuropsychological and develop a comprehensive system for examining children to study their readiness for mastering writing in bilingual conditions.

2. The specificity of the pattern of violation of the letter in bilingual children consists in: a) eclecticism, i.e. the presence of distortions typical of various generally recognized forms of dysgraphia; b) the existence of errors due to linguistic interference resulting from the lack of mastery of none is native language in which learning conducted [7].

3. According to the neuropsychological study of children, among the factors that complicate their learning in the bilingual environment are those that an insufficiently formed for the higher mental functions that are basic for mastering the letter. The presence of primary gnostic and paraxial features in children of primary school age makes it necessary in addition to a logaoedic neuropsychological correction. This is important not only in terms of bilingual but also in monolingual education [8].
4. A system has been developed for preventing and overcoming dysgraphia in bilingual children, which is productive, provided that it includes renowned methods of speech therapy correction, as well as those aimed at strengthening both language systems and eliminating language interference phenomena in the letter.

5. Testing the system of correctional education provided a positive result, which consists of reducing the number of specific and none is specific dysgraphia errors and, accordingly, in improving the performance of children [9].

Thus, as a result, of the study, the validity of the hypothesis confirmed, all the tasks set solved; their compliance with the purpose of the study proved.

Recently, experience has been gained that testifies that it is easier for some children to learn to read using the traditional method is analytical, or otherwise alphabetic is alphanumeric, and others are the method of global reading. The first can be called left hemisphere; the second is a right hemisphere. Our study, although it did not set a particular task to study the peculiarities of teaching children with different ratios of functional hemispheric activity, confirmed that some children, not knowing the letters, easily recognize familiar words and even sentences in books. Some of them, without overcoming all the letters, begin to read rather fluently. Among such children, there are a lot of visible (not hidden) left-handers and ambidexters. Other children are not capable of this method. It is easier for them to memorize individual letters, put them in syllables, syllables in words. At the beginning of training, it is essential to follow the innate features of the brain organization of mental functions [10].

\section{CONCLUSION}

Kazakhstan universities students do believe that compared with other language English is not difficult language. Pedagogical implications of this study are: firstly, understanding of the learner's beliefs about English language learning may help learners to identify their negative effect on language learning [11].

Thus, it is advisable to carry out a preliminary diagnosis of which of the cerebral hemispheres should be the leading one at the initial stage of learning to read, and accordingly, this or that pedagogical tactic should be applied. Subsequently, both groups of children must master both analytical and global 
reading. The question is to choose one of them as the initial one.

For the successful prevention of dysgraphia and dyslexia in children, it is necessary to identify the prerequisites for the child. In this regard, it is required to determine:

1. The state of auditory differentiation of acoustically close sounds, the violation of which is considered as a prerequisite for acoustic dysgraphia (or dysgraphia based on a breach of phonemic recognition).

2. State of sound pronunciation (especially in terms of complete sound replacements, which are a prerequisite for articulatory is acoustic dystrophic).

3. The formation of primary types of phonemic analysis of words available to children of preschool age. Its absence is the prerequisite for discord based on the incomplete form of phonemic analysis and synthesis of words.

4. Formation of visual is spatial representations and visual analysis and synthesis, the insufficiency of which indicates the presence of prerequisites for optical dysgraphia.

5. The state of vocabulary and grammatical structure of speech, a noticeable lag in the development of which is a prerequisite of aromatic dysgraphia.

6. To take into account that children who have changed the language of instruction are at risk of dyslexia and dysgraphia and should receive individual assistance in mastering a second language.

Thus, as a result, of the conducted research, the validity of the hypothesis was confirmed, the tasks were solved; their compliance with the purpose of the study was proved.

\section{ABBREVIATIONS}

$$
\begin{aligned}
& \text { AAC }=\text { Augmentative and Alternative Communication } \\
& \text { ID }=\text { Intellectual disabilities } \\
& \mathrm{KZ} \quad=\text { Kazakhstan }
\end{aligned}
$$

\section{REFERENCES}

[1] Mirenda P. Toward Functional Augmentative and Alternative Communication for Students With Autism. Lang Speech Hear Serv Sch 2003; 34(3): 203-216. https://doi.org/10.1044/0161-1461(2003/017)

[2] Brownlee A, Palovcak M. The role of augmentative communication devices in the medical management of ALS Neurorehabilitation 2007; 22(6): 445-450.

[3] Light JC, Roberts B, Dimarco R, Greiner N. Augmentative and alternative communication to support receptive and expressive communication for people with autism. J Commun Disord 1998; 31(2): 153-180. https://doi.org/10.1016/S0021-9924(97)00087-7

[4] Aliev R, Kazhe N. Bilingual education: Theory and practice. Retorica A 2005; p. 384

[5] Akhutina TV, Inshakova OB. Neuropsychological diagnostics, examination of writing and reading of younger schoolchildren. M.: Sekachev, 2008; p. 128.

[6] Bagirokov KhZ. Bilingualism: theoretical and applied aspects (on the material of the Adygei and Russian languages): Monograph. Maikop: ASU, 2004; p. 316

[7] Badalyan LO. Children's neurology. M.: Enlightenment 2003; p. 230.

[8] Crutchley A, Botting N, Conti-Ramsden G. Bilingualism and specific language impairment in children attending language units. Int J Lang Commun Disord 1997; 32(2): 267-276. https://doi.org/10.3109/13682829709020409

[9] Yu. Barsukova L, Rumega N, Zemskaya N. Speech therapy for teachers and psychologists of parents. M. Phoenix 2010; p. 316.

[10] P. Bekker LM. Mind and reality. Unified Theory of Mental Processes, M.; Meaning 2008; p. 685.

[11] Orynbek, Gulnar, Dauletali, A. Farida, Orazakynkyzy, L. Koishigulova, Zh. Bissenbayeva. The Foreign Language Students' Beliefs Regarding Learning Strategies In Different Kazakhstan University Students. Journal of Intellectual Disability - Diagnosis and Treatment 2018; 6: 96-104. https://doi.org/10.6000/2292-2598.2018.06.03.5

Received on 31-05-2019

DOI: https://doi.org/10.6000/2292-2598.2019.07.03.8

(c) 2019 Sholpan et al.; Licensee Lifescience Global.

This is an open access article licensed under the terms of the Creative Commons Attribution Non-Commercial License (http://creativecommons.org/licenses/by-nc/3.0/) which permits unrestricted, non-commercial use, distribution and reproduction in any medium, provided the work is properly cited. 